\title{
COMMENT
}

\section{October ECI biocommentary}

\author{
Imran Nazir Mir ${ }^{1}$ \\ Pediatric Research (2019) 86:419; https://doi.org/10.1038/s41390-019-0478-5
}

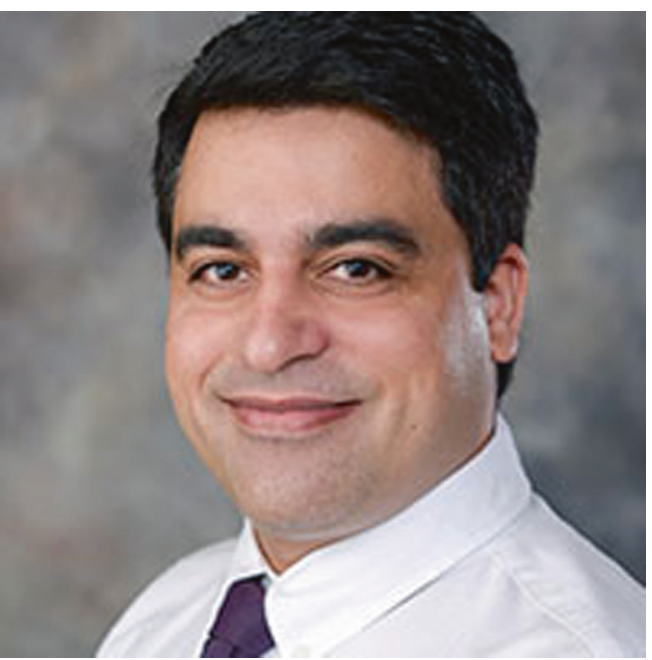

I grew up in beautiful, but troubled valley of Kashmir, which is located between the Great Himalayas and the Pir Panchal Range in the Indian subcontinent. I went to a medical school in Kashmir, called Government Medical College Srinagar. Due to the political turmoil in Kashmir, I left my birthplace in pursuit of an academic career and came to the United States of America after qualifying USMLE exams. I completed my internship and pediatric residency at the Oklahoma University Children's Hospital, Oklahoma City. Then, I obtained my training in Neonatal-Perinatal Medicine at University of Texas Southwestern, Dallas. After completing my Neonatal-Perinatal Medicine fellowship in 2015, I was recruited as faculty member in the division of Neonatal-Perinatal Medicine at UT Southwestern Medical School; and I am currently working as an Assistant Professor of Pediatrics in the same institute.

My intense desire to help children started when I entered my clinical years in medical school. I was able to work with children in a long-term medical setting, and their innocent faces would brighten up my day. Each day I was grateful to have the opportunity to help another sick child.

My first research project during pediatric residency was a clinical study, looking at the role of plasma osmolality in intraventricular hemorrhage (IVH) in extremely preterm infants. This got me interested in neonatal brain research. During my neonatology fellowship, I reported that chronic inflammatory placental pathologic lesions are associated with poor neurodevelopmental outcomes in neonates with moderate to severe hypoxic ischemic encephalopathy, who received systemic hypothermia treatment. I then sought to determine if the inflammatory cytokines previously identified in association with fetal hypoxia-asphyxia and neonatal encephalopathy were actually derived from the mother and/or placenta, which was the "conventional wisdom". In these studies, I observed that the inflammatory cytokines IL- 6 and -8 were actually derived from the fetus and associated with $100 \%$ nonsaturable placental clearance. Thus, the conventional wisdom was incorrect! These data lead me to design this study to look at the role of placental synthesis/clearance of neurobiomarkers (GFAP and UCH-L1) for neonatal encephalopathy. My mentors, Lina Chalak and Charles Rosenfeld, have a big contribution in shaping up my academic career.

My advice to those coming along behind me is that passion, hard work, and perseverance are the key ingredients to success in academic medicine. You might not get there the same way as others, but you will get there.

\section{ADDITIONAL INFORMATION}

Conflict of interest: The author declares that he has no conflict of interest.

Publisher's note: Springer Nature remains neutral with regard to jurisdictional claims in published maps and institutional affiliations.

${ }^{1}$ University of Texas Southwestern Medical Center at Dallas, Dallas, TX, USA

Correspondence: Imran Nazir Mir (Imran.mir@utsouthwestern.edu)

Received: 10 June 2019 Accepted: 16 June 2019

Published online: 24 June 2019 